\title{
Public Preferences for Planting Genetically Improved Poplars on Public Land for Biofuel Production in Western Canada.
}

\begin{tabular}{|r|l|}
\hline Journal: & Canadian Journal of Forest Research \\
\hline Manuscript ID & cjfr-2015-0217.R1 \\
\hline Danuscript Type: & Article \\
\hline Complete List of Authors: & $\begin{array}{l}\text { Rollins, Curtis; University of Alberta, Resource Economics \& Environmental } \\
\text { Sociology } \\
\text { Boxall, Peter; University of Alberta, Resource Economics \& Environmental } \\
\text { Sociology } \\
\text { Luckert, Martin; University of Alberta, Resource Economics \& } \\
\text { Environmental Sociology }\end{array}$ \\
\hline Keyword: & Biotechnology, Biofuels, Public Preferences, Public Land, Poplar Plantations \\
\hline & \\
\hline
\end{tabular}

SCHOLARONE

Manuscripts 
6 Public Preferences for Planting Genetically Improved Poplars on Public Land for 7 Biofuel Production in Western Canada.

9 Curtis Rollins, Peter C. Boxall and Martin K. Luckert

Department of Resource Economics and Environmental Sociology, University of Alberta, 515

Corresponding author: Peter Boxall (e-mail: pboxall@ualberta.ca). 
16 Public Preferences for Planting Genetically Improved Poplars on Public Land for

17 Biofuel Production in Western Canada.

19 Abstract

20 We examine public opinion of planting genetically improved poplars on public lands in western

21 Canada. Policy scenarios consider the use of three different breeding methods (traditional

22 selective breeding, genomics-assisted breeding, and genetic modification), each with and without

23 poplars being used for biofuels. We employ a choice experiment to provide alternative outcomes

24 to policy scenarios and to investigate differences among characteristics of respondents. Overall, a

25 majority of respondents voted in favour of policies that allowed improved poplars on public land,

26 if fibre is used to generate biofuels. Adding biofuel production to a policy scenario increases the

27 probability of acceptance by $17-32 \%$. In contrast, the various types of breeding technology do

28 not matter as much regarding public acceptance. Responses differ among segments of the

29 population, but these differences do not greatly influence choices. Attributes that increase the

30 probability of acceptance are: being a male, being from Alberta, and being from a population

31 centre of $10,000-100,000$ people (relative to centers $>100,000$ ). Attributes that decrease the

32 probability of acceptance are: age, being from British Columbia, and being from a population

33 centre of $<10,000$ (relative to centers $>100,000$ ). Despite these significant patterns of

34 preferences, there is substantial uncertainty underlying responses.

36 Key words: Biotechnology, Biofuels, Public Land, Public Preferences, Poplar Plantations 


\section{Introduction}

Genomic and tree-breeding research has been conducted in hopes of achieving a variety

41 of desired outcomes, including pest-resistance, climate-change adaptation, or increasing wood

42 quality and volume (Genome Canada 2014). One specific project, POPCAN, aims to harness

43 genomic information to improve the suitability of poplars (Populus Spp.) as a cellulosic biofuel

44 feedstock (Genome British Columbia 2014). Canadian demand for biofuels is being spurred by

45 the Government of Canada's 2010 Renewable Fuel Standard, which requires an average of 5\%

46 renewable alcohol be blended into gasoline fuel to mitigate greenhouse gas emissions (Minister

47 of Justice 2013). Though the requirements of the standard are currently being met with ethanol

48 made from corn and wheat, there are ethical concerns about using food for fuel, as it results in

49 higher food prices (Pimentel et al. 2009). If a new cellulosic ethanol industry were to emerge,

50 fibre from forest resources could contribute towards meeting the requirements of the Renewable

51 Fuel Standard. Poplars may become an even more attractive ethanol feedstock moving forward,

52 with Canadian pulp and paper production in decline (Bogdanski 2014) and an abundance of

53 public forest land in Canada.

As genomics research may have transformative impacts on society, Genome Canada uses

55 a framework examining such research on ethical, environmental, economic, legal, and social

56 (GE ${ }^{3} \mathrm{LS}$ ) grounds (Genome Canada 2015). This component of genomics research is essential in

57 identifying and understanding challenges and opportunities related to applications of genomics,

58 and therefore the feasibility of these applications coming to fruition. For the case of POPCAN,

59 assuming appropriate technology can be developed, using forest sources for biofuel feedstock

60 could be controversial. In Canada 93\% of forested land is publicly owned, which is subject to

61 regulations regarding the types of trees that may be planted (Natural Resources Canada 2012). 
62 Specifically, most provinces seek to re-establish forests similar to ones harvested, by requiring

63 that trees planted on public land come from seed collected within a certain range of the planting

64 site. For example, 90 seed zones are defined in Alberta (Alberta Environment and Sustainable

65 Resource Development 2009). Such systems preclude the use of genomics technology which

66 relies on creating improved varieties from limited sources of parent material for widespread

67 planting. Therefore, forest policy would need to change to allow these new trees to be planted on 68 public lands. ${ }^{1}$

If POPCAN research were to be applied on Canadian public land, a variety of different

70 outcomes could be realized. On one hand, POPCAN could result in a more prosperous forest

71 industry and could aid Canada in reducing greenhouse gas emissions. On the other hand,

72 replacing large portions of public land with non-native trees could result in genetic flow from

73 improved poplars to native poplars, resulting in uncertain environmental consequences (Guigou-

74 Cairas 2008). Public perceptions of the technology used to create improved poplars, and its use

75 on public lands, will likely be important factors influencing future public land forest policy,

76 which will ultimately determine the extent to which poplar genomics technology is adopted in

77 Canada.

${ }^{1}$ Another option could be to establish poplar plantations on private agricultural lands. However, such a practice could re-ignite concerns regarding food for fuel tradeoffs. Moreover, financial analysis indicates that, given current end product prices and costs, poplar plantations will have a difficult time competing with agriculture for land (Shoostarian 2015). 
This paper seeks to measure public preferences for planting various types of hybrid or

79 genetically improved poplars on public land in the four western Canadian provinces. To assess

80 public preferences, a number of hypothetical policies surrounding tree breeding and biofuel

81 production were developed, along with estimates of their potential effects. The policy options

82 and associated effects were presented to representative samples of provincial residents using

83 internet panel surveys. The respondents were asked to vote between their province's current

84 forest policy and the proposed policies in an iterated series of hypothetical provincial

85 referendums. Proposed policy options were associated with one of three poplar breeding

86 improvement methods that could be planted on public land, each with and without resulting

87 poplar-derived biofuels. This methodological approach permits understanding of levels of

88 acceptance between different policy options dependent on their outcomes. Specifically,

89 preferences for different poplar breeding methods will be investigated, both within and outside

90 the context of using poplar as a biofuel source. Further, understanding will be gained with

91 respect to why such policies may or may not be preferred, and which members of the public are

92 more willing to support them.

93

\section{Literature Review}

95 While there are numerous studies of public perceptions of or preferences for

96 biotechnology applications in food and health (see reviews by Costa-Font et al. 2009, and Pin \&

97 Guttelling 2009), few have specifically examined applications to forestry. One source of

98 incompatibility between this study and food or health biotechnology preference studies is the

99 presence of private health concerns associated with food or medicine purchase decisions, as the

100 products are to be ingested by humans. Thus, while underlying determinants of forest 
101 biotechnology preferences can be informed by food-related studies, it is expected that many

102 relationships typically found in the literature may not hold in this context.

103 Only two studies have examined public perceptions of applications of genomics in

104 Canadian forestry. The first, by Harshaw (2012), examined the BC public's acceptance of poplar

105 plantations to be used as biofuel feedstock. He found that $44 \%$ of the BC public agreed with

106 large-scale poplar plantations being used to provide biofuel feedstock on private land (29\%

107 disagreed, and 26\% were uncertain), while only 15\% agreed with replacing natural forested

108 public land with plantations aimed at biofuel production (66\% disagreed, and 19\% were

109 uncertain). The second study, by Hajjar et al. (2014), gauged public acceptance of using a variety

110 of breeding methods and strategies to adapt public forests to climate change in BC and Alberta.

111 The authors found that a strong majority of the public accepted replanting local seedlings or

112 selectively breeding with local seed, while higher levels of breeding technology (genomics-

113 assisted breeding and genetic modification) and breeding with non-local seeds were accepted by

114 approximately $50 \%$ of respondents. A general trend of decreasing acceptance was found as the

115 level of breeding technology increased, though the Alberta and BC publics were found to be least

116 accepting of allowing the forest to grow back naturally without replanting efforts.

117 One key difficulty in gauging public preferences for genomics technology and forest-

118 based biofuel is associated with a lack of knowledge regarding what a proposed change could

119 entail. For example, what changes would planting trees, created with advanced genetic

120 technologies, have on forests, the forest industry, and the broader economy? Along these lines,

121 Hajjar et al. (2014) found that many respondents would change their opinions depending on the

122 economic, environmental, social, or aesthetic changes created by different policies. Yet no study

123 to date has attempted to measure these public perceptions in the context of defined outcomes. 
124 The closest example is a study by (Susaeta et al. 2010) who examined how potential outcomes

125 associated with forest-based biofuels affect acceptability of bio-refineries. Environmental

126 benefits (sustainability or reduction in carbon emissions) were positively linked with biofuel

127 acceptance. In another study, Marciano et al. (2014) found that respondents who perceived

128 forest-based bio-refineries as environmentally or economically beneficial were more likely to

129 accept bio-refineries.

$130 \quad$ Few studies have been conducted on public preferences for forest biotechnology in

131 relation to individual specific characteristics. Hajjar et al. (2014) detected minimal differences in

132 forest biotechnology acceptance explained by demographic variables. Males were more likely to

133 accept GM trees; Albertans were more likely to accept not planting seedlings post-harvest than

134 British Columbians; and respondents living outside of major cities were more likely to accept

135 policies involving more human intervention. In an assessment of risks to forest biodiversity,

136 McFarlane (2005) found that more educated respondents perceived higher levels of risk related

137 to forestry activity and land conversion, and females and older respondents perceived higher

138 levels of risk associated with land conversion. Studies of public preferences for forest-based

139 biofuels in the United States also found inconsistent relationships with characteristics of

140 individuals. In a three-state sample (Arkansas, Florida, and Virginia), few results were consistent

141 between samples (Susaeta et al. 2010). A higher education level was a significant positive

142 predictor of forest-based biofuels in one sample, while older respondents were less likely to

143 accept biofuels in one sample. In another American study, Marciano et al. (2014) found that

144 more educated individuals were less likely to accept forest-based biofuels. Overall, results of

145 forest biotechnology public opinion studies seem largely affected by specific contexts. 
146 Further questions arise regarding how public preferences may vary among different

147 segments of the population. In food biotechnology studies, numerous authors have found strong

148 relationships between acceptance and factors such as sex, age, or education, while many others

149 have found no significant links (see review by Costa-Font et al. 2008). These results may be

150 explained by regional and product differences. However, more consistent relationships are often

151 found between attitudes or values, such as environmental concern or trust in government and

152 industry, and biotechnology preferences or risk perceptions (Costa-Font et al. 2008). Many

153 studies have relied on, for instance, the Fishbein Multi-attribute Model (1963), which theorizes

154 that perceptions of a product or policy is determined by its associated perceptions of benefits and

155 risks, which are in turn affected by social-cultural factors, attitudes, or values. Attitudes

156 commonly examined as determinants of benefit or risk perceptions, and therefore preferences for

157 biotechnology, include trust in agencies and regulations, views on science or the environment.

158 When viewing public preferences from this standpoint, it is understandable that observable

159 individual-specific characteristics, such as age or gender, exhibit inconsistent relationships with

160 evaluations of biotechnology, as relationships between demographics and attitudes or values

161 often vary by region and context.

163 Methods

164 In order to address the gaps identified in the literature, we measure public preferences for

165 different forest policies and management practices, conditional on their predicted outcomes. This

166 method enables us to present different tree breeding options and their potential effects on society

167 to the public; measuring policy preference while taking these effects into account. 


\section{Questionnaire Design}

170 Questionnaire design involved numerous stages of consultation with scientific experts

171 (geneticists, botanists, and forest scientists) and the general public. First, four focus groups were

172 held to assess the public's understanding of the forest and biofuel topic and to present an early

173 draft of hypothetical referendum question formats. These formats outlined attributes and impacts

174 of various policy options relative to the current public land policy involving replanting of trees.

175 Participants for all public focus groups were recruited by telephone using random-digit-dialing

176 by Advanis Inc., an Edmonton-based market research firm. Two focus groups each were held in

177 Edmonton (16 participants) and Grande Prairie, Alberta (17 participants). Next, a survey was

178 sent to a group of forestry experts to gather data on predicted changes in poplar growth rate and

179 value arising from different breeding methods. Draft scenarios for hypothetical referendums

180 were developed based on the expert estimates of increases in growth and value of poplars using

181 different breeding methods. A discussion was then held with a group of experts involved with

182 POPCAN to ensure the information provided in the questionnaire was accurate. Following

183 further reviews, a final round of public focus groups were held; two groups in Edmonton,

184 Alberta (24 participants) and two in North Battleford, Saskatchewan (22 participants). This

185 round of focus groups aimed to ensure that all elements of the questionnaire were understood,

186 and to reduce potential sources of bias.

187 After completing these phases and resulting edits to the questionnaire, a pre-test version

188 was administered online to 102 members (51 Albertans and 51 British Columbians) of an

189 internet panel maintained by Ipsos Canada, a market research firm. The final questionnaire

190 briefly explained information about biofuels, different tree breeding methods, and the relevant

191 province's current forest composition, industry, and policy. Next, a series of hypothetical 
192 referendum questions were presented with follow-up questions, and demographic information

193 was collected last. Details of the questionnaire are available in Rollins (2015).

194 In total, six proposed policy scenarios were created for the referendum tasks. The six

195 proposed policy scenarios were driven by two key attributes: the tree breeding method employed,

196 and whether or not poplars would be used for biofuel production. Biofuel production $(B F)$ was

197 considered a binary variable with its presence or absence in a particular policy. The three

198 breeding methods examined were traditional selective breeding (Trad), genomics-assisted

199 breeding (Genome), and genetic modification (GM). Each breeding method appeared in one

200 proposed policy scenario with or without biofuel production. Each voting scenario was set up as

201 a provincial referendum, where respondents were asked to vote for the new proposed policy, or

202 to reject the new policy and maintain the current policy. An example referendum question is

203 presented in Figure 1.

204 As shown in Figure 1, supplemental information was presented for each referendum

205 question in addition to the breeding method and biofuel production policy attributes. The

206 additional information was selected based on focus group discussions during the survey

207 development phase. The first row of information supplied in figure 1 involves the region where

208 parent trees are located. All proposed policies (right-most column) involved worldwide seed

209 selection for improved poplars, while the current policy involved a small amount of selectively

210 bred poplars (on less than $0.1 \%$ of land) using local breeding stock to represent breeding trials in

211 each province.

212 The next row of information involves how commercial public forest land is currently

213 used, and how it would change with new policies. Estimates of commercial public forest land-

214 use are comprised of non-harvested land (i.e. non-protected land with no future harvest plans), 
215 and land with coniferous trees, natural poplars, and improved poplars predicted to be harvested

216 in the future. In the referendum exercise, harvested coniferous treed land was held constant for

217 the current and all proposed policies, while harvested natural poplar land referred to harvested

218 land regenerated naturally via roots and seeds of harvested poplars.

219 Current commercial forest land-use was calculated for each province using a variety of

220 sources, depending on data availability. British Columbia forest land-use was calculated using a

221 collection of 40 timber supply area analysis reports prepared by the British Columbia Ministry of

222 Forest, Lands, and Natural Resource Operations (2014), and Alberta forest land-use was

223 calculated based on data from Alberta Environment and Sustainable Resource Development

224 (2013). For Saskatchewan and Manitoba, data was not easily available from the provincial

225 governments, so land-use was estimated based on information released by forestry firms ${ }^{2}$.

226 Predicted changes in land-use arising from allowing different breeding methods and worldwide

227 seed selection on public land were derived using simulation results from Anderson et al. (2012).

228 All policies used in the referendum exercise assumed an equal annual-allowable-cut (AAC),

229 implying that the same volume of timber is harvested in each scenario. Technically, higher tree

230 growth rates could imply a higher AAC instead of leaving some areas un-harvested, but a

231 constant AAC is assumed to avoid confounding the area planted to genetically improved poplars

232 with different tree breeding methods.

233 The referendum scenarios (Fig. 1) also include a row that considers impacts of proposed

234 policies on industry. Four categories describe the impacts depending on the gains associated with

235 different breeding methods: little to no, small, moderate, and strong positive impacts. The impact

${ }^{2}$ Reports from Mistik Management Ltd. (2013) and Saskaw Askiy Management Inc. (2013) for Saskatchewan, and reports from LP Canada Ltd. (2014) and Tolko Industries Ltd. (2014) for Manitoba 
236 of allowing new tree breeding methods on the forest industry (jobs and income) was estimated

237 using a combination of results from Anderson et al. (2012), the expert tree growth and value

238 survey, and forest industry composition in each province (proportion of hardwood to softwood

239 production from Natural Resources Canada (2009) and current land-use). The forest industry is

240 likely to benefit from the proposed policies due to increases in poplar growth rates and values

241 associated with higher technology breeding methods.

242 The last row in the referendum scenarios involved carbon emissions. Reductions in

243 carbon emissions arising from replacing gasoline with poplar-derived biofuels were represented

244 by the estimated equivalent in cars driven per year. Calculated reductions are based on $5 \%$ of

245 each province's gasoline being replaced by Poplar-derived biofuel, using a low (65-70\%)

246 estimate of life-cycle analysis carbon emission reduction of second-generation biofuels from

247 Schmer et al. (2008), forest industry production statistics (Natural Resources Canada 2009), and

248 provincial gasoline consumption data from Statistics Canada (2013).

249 To avoid overwhelming respondents with excessively complicated scenarios, we aimed

250 to keep the voting exercises simple and limited the number of new policies. Thus, while it could

251 be informative to allow land-use, impact on industry, and changes in carbon emissions to freely

252 vary in the policy choices, these attributes were considered to be strictly correlated with the

253 breeding method and biofuel production attributes. Since only two policy attributes of the five

254 listed in the hypothetical referendums freely vary (breeding method and biofuel production),

255 only the importance of these attributes can be analyzed using a choice model (see the

256 econometric methods section below). In order to gather information on other policy attributes,

257 respondents were asked to indicate how important each policy attribute was when deciding on 
258 their vote choice using a five-point Likert-type item (with options not at all important, not

259 important, neutral, important, and very important).

260 Policy attribute levels associated with each policy for each province are listed in Table 1.

261 Policy attribute levels associated with each policy for each province are listed in Table 1. Given

262 the simple design where, in essence, only two policy attributes (one with three levels and one

263 with two levels) varied with other attributes correlated with the combination of the two, a full

264 factorial design was employed, meaning that each respondent was presented with all of the

265 possible combinations of the two varying attributes $(\mathrm{N}=6)$. These referendum scenarios were

266 presented to each respondent in a randomized order to reduce the potential for ordering effects.

267 A hypothetical referendum approach was chosen as it has been found to be an accurate

268 predictor of real referendum outcomes (Vossler et al. 2003), and is considered to be incentive

269 compatible $^{3}$ (Carson \& Grooves 2007). However, there are potential issues with the hypothetical

270 referendum approach. Hypothetical means of measuring choices may lead to biased responses.

271 To investigate the robustness of voting results, additional questions were included. After each

272 referendum question, respondents were asked to rate how certain they were of their vote on a

273 four-point Likert scale (very uncertain, somewhat uncertain, somewhat certain, and very

274 certain). Past studies have found that those who are very certain often provide realistic results,

275 while other responses are less reliable (Blumenschein et al. 1998; Ready et al. 2010).

\section{Questionnaire Administration}

277 The questionnaire was administered online to members of an internet panel maintained

278 by Ipsos Canada, a market research firm. The goal was to obtain a representative sample of the

279 Alberta, British Columbia, Manitoba, and Saskatchewan populations. Using an online format

${ }^{3}$ If it is in a respondent's best interest to respond to a mechanism truthfully, the mechanism is incentive compatible. 
280 allowed for: color graphics in the information and hypothetical referendum sections; randomized

281 orders of hypothetical referendum questions; and hyperlinks to information and definitions to aid

282 in answering choice questions. The internet panel maintained by Ipsos Canada consists of over

283200,000 members, representative of the Canadian population based on demographic information.

284 Participants were recruited with quotas on age, gender, and municipality population to increase

285 each province's sample representativeness of its population demographics. To decrease sampling

286 bias within the panel, respondents were provided with an incentive from Ipsos Canada, and were

287 not informed of the study topic when invited to participate. Internet surveys may face issues of

288 sampling bias, as internet access is a requirement. However, an increasing proportion of

289 Canadians are accessing the internet at home over time. In 2012, 83\% of Canadians had internet

290 access, an increase from 79\% in 2010 (Statistics Canada 2013).

\section{Econometric Methods}

292 Economic theory posits that individuals seek to maximize utility, and will therefore

293 choose the policy that makes them best off. Equation 1 represents the binary choice model for

294 respondent $n$ evaluating choice $m$. With a binary dependent variable, where the observed choice

$295 C_{n m}=1 \mathrm{implies}$ a vote in favor of a proposed policy, and $C_{n m}=0$ implies a vote for the current

296 policy, $U_{n m}$ then denotes the latent utility associated with voting in favor of a proposed policy

297 over the current policy.

$$
U_{n m}=\alpha+\beta^{\prime} X_{n}+\gamma^{\prime} P_{m}+v_{n m}
$$

where $C_{n m}=1$ if $U_{n m}>0$, and $C_{n m}=0$ otherwise.

In equation $1, X_{n}$ is a vector of respondent-specific characteristics, $P_{m}$ is a vector of

300 policy-specific variables, $\alpha, \beta$, and $\gamma$ are estimated coefficients, and $v_{n m}$ is a mean-zero,

301 normally distributed error term. $C_{n m}$ is the observed vote choice of respondent $n$ evaluating vote 
$302 m$, and is expected to equal one if $U_{n m}$ is positive, and zero otherwise. That is, it is predicted that

303 a respondent will vote in favor of a new policy if the act grants them positive utility, and will

304 vote in favor of the current policy if a vote for the new policy grants negative utility.

305 Equation 1 is estimated using a binary probit model. Since there are six responses per

306 respondent, it is expected that error terms of the responses for each person will be correlated. To

307 address this issue, a robust cluster-corrected Huber-White sandwich estimator is employed

308 (Huber 1967; White 1980), which allows for $v_{n m}$ to be correlated for each cluster $n$, but assumes

309 each cluster of error terms are uncorrelated with one another.

\section{$310 \quad$ Results \& Discussion}

311 Sample and population demographics are outlined in Table 2. Sample sizes vary by

312 province because of differing population sizes and according to the ability of Ipsos to secure

313 participants while maintaining representativeness with respect to age, gender and

314 location/population centre. Females were slightly over-sampled relative to males in all provinces.

315 In $\mathrm{AB}$ and $\mathrm{BC}$, large cities (population greater than 100,000) were under-sampled, while small

316 and medium cities were somewhat over-sampled. Samples and populations are very similar for

317 MB and SK with respect to population centre sizes. In general, all samples have higher post-

318 secondary education rates than their respective populations. However, it is likely that population

319 education rates are slightly higher than listed, as the population data refers to all Canadian

320 residents over 15 years of age, whereas our sample is based on individuals over 18 years of age.

321 Most respondents took between 15 and 30 minutes to complete the survey, and one observation

322 was dropped for completing the survey in what we judged to be too quickly (less than 10

323 minutes). 
325 displayed in Figure 2. New policies that assure that 5\% of a province's gasoline sales would be 326 replaced by poplar-derived biofuels (i.e. $\operatorname{Trad}+B F$, Genome $+B F$, and $G M+B F$ ) are favored

327 by a majority of respondents in most provinces, with the one exception occurring in British

328 Columbia for $G M+B F$. If biofuels are not included in a policy scenario, numbers drop

329 significantly with approximately $25 \%$ to $45 \%$ of respondents voting for change. Differences

330 between the policy scenarios within each province when no biofuels are included are $5 \%$ or less,

331 implying that the public may be indifferent between the breeding technologies. However, when

332 comparing policy situations that involve biofuel production, GM seems to be less preferred than

333 other breeding methods, particularly in British Columbia. This result could imply that some who

334 support biofuel production do not support GM technology use in forestry. When comparing the

335 provinces, Albertans voted in favor of a new policy over the current policy most often, while

336 British Columbians voted in favor of a new policy least often.

337 Voting results of respondents who were very certain of their choice are outlined in Figure

338 3. Analyzing very certain responses is typically done in stated-preference willingness-to-pay

339 studies, as this practice is thought to correct for response bias arising from hypothetical nature of

340 the question (Ready et al. 2010). Depending on the province and voting scenario, respondents

341 were very certain of their voting choice $20-25 \%$ of the time. The generally low level of certainty

342 may indicate that the public is not very engaged in understanding forest biotechnology and

343 breeding ${ }^{4}$. However, this result may also be interpreted as evidence that the public is aware of the

${ }^{4}$ When asked, $60 \%$ of respondents stated that they at least "somewhat understand" the three tree breeding methods being examined, while $42.5 \%$ stated they were at least "somewhat informed" about forest management. 
344 uncertainty of the effects of new forest policies ${ }^{5}$. Voting trends of very certain respondents are

345 quite similar to the pooled results in Figure 2, but are approximately $10 \%$ lower in most cases.

346 The largest disparity between all and only very certain respondents is in the BC sample for all

347 policy scenarios. Very certain respondents from all provinces are less accepting of new policies

348 resulting in no poplar-derived biofuels relative to votes of all respondents. For the $\operatorname{Trad}+B F$

349 policy, the reduction in public approval for very certain responses is minimal for $\mathrm{AB}, \mathrm{MB}$, and

350 SK, but the disparity grows for breeding methods involving higher degrees of human control.

351 Taking the results from Figures 2 and 3 into account, there seems to be substantial

352 support for new forest policies over the current policy when biofuels are part of scenarios.

353 Though these policies attract support from a majority of respondents, support levels become

354 somewhat deflated when only taking very certain responses into account. Excluding less certain

355 responses is often effective in reducing bias in responses due to the hypothetical nature of stated

356 preference methods (Ready et al. 2012), so it is possible that the very certain results are a more

357 accurate reading of preferences.

358 Results from two probit models, one using all responses and one only using very certain

359 responses, are listed in Table 3. In both models, the observed dependent variable equals 1 if the

360 respondent voted in favor of the new proposed policy, and 0 if the current policy was chosen.

361 The models provide statistical tests to differentiate between vote totals presented in Figures 2 and

3623 , and also provide insights on how respondent-specific variables affect voting likelihoods. The

363 third column for each model lists the marginal effect. For continuous variables, the marginal

364 effect represents the change in likelihood of voting in favor of a new policy over the current for a

\footnotetext{
${ }^{5}$ In a follow-up question to the referendum questions, $50 \%$ of respondents who voted in favor of the current policy at least once stated it was partly because they required more information about the policy to consider voting for it.
} 
365 one-unit change in the explanatory variable. Binary provincial and policy variables are effect-

366 coded to ease with interpretation, so the marginal effect reflects the change in likelihood of

367 voting in favor of a new policy for a province or policy relative to the average likelihood of

368 voting in favor of a new policy. Explained variance (pseudo- $\mathrm{R}^{2}$ ) doubles when excluding

369 responses that are not very certain, though only $24 \%$ of responses and $45 \%$ of respondents are

370 represented in this model. The percent of correct predictions also improves in the very certain

371 model, up to $68 \%$ from $61 \%$.

372 In the all responses model, policy scenario variables play a large role in predicting the

373 probability of voting in favor of a new policy over the current policy, while demographic

374 characteristics play a smaller role. Relative to the base policy scenario (Trad no BF), all other

375 new policies were more preferable at or above the $95 \%$ confidence level. Adding biofuel

376 production to the traditional breeding policy increases the likelihood of a respondent voting in

377 favor of a new policy over the status-quo by $27 \%$. This increased likelihood of public support

378 decreases as more human control is involved in tree breeding, where a respondent is $25 \%$ more

379 likely to vote for genome $+B F$ and $19 \%$ more likely to vote for policy $G M+B F$ in comparison

380 to $t r a d+B F$. A respondent is $4 \%$ more likely to vote for either genome no BF or GM no BF

381 compared to the trad no BF policy. For the model including only very certain responses, there is

382 no significant difference between policies that do not include poplar-derived biofuels. The

383 likelihood of accepting a new policy with poplar-derived biofuels relative to policy scenario

384 Trad no BF is slightly higher than in the first model for policies Trad $+B F$ and Genome $+B F$

385 (32\% and $27 \%$, respectively). The $G M+B F$ policy is $16.5 \%$ more likely to be chosen in

386 comparison to Trad no BF, which is a smaller magnitude than in the all responses model. 
The general lack of significant differences between no $B F$ policy scenarios may be due to

388

389

390

391

392

393

394

395

396

397

398

399

400

401

402

403

404

405

406

407

408

409

tradeoffs associated with policies. . It is assumed that the increased risk and uncertainty of applying biotechnology applications are inherently represented by the breeding method and seed source (worldwide) attributes. However, these risks were also packaged with increased benefits. Thus, it seems that members of the public are weighing the increased risks and benefits of proposed policies relative to the current policy, and evaluating how these factors affect their utility when choosing their preferred policy.

Wald tests were used to test the effect of using poplars as a biofuel source on policy preferences. For each model, tests were conducted with the null hypothesis that the coefficients for the $n o B F$ and $+B F$ policies for each breeding method are equal (e.g. equality between Genome no BF and Genome $+B F$ coefficients). In every test, the null hypothesis was rejected at the $99 \%$ confidence level, implying that the use of poplars as a biofuel source significantly increases public preference for the application of forest biotechnology on public lands. That is, biotechnology is perceived as being more palatable if combined with an environmental benefit. Other studies have similarly shown that preferences or willingness to pay for non-food products increase in light of environmental benefits or reduced carbon footprints (Michaud et al. 2013), or that GM food products are valued more highly in light of benefits offered to the consumer (Lusk et al. 2005). Hajjar et al. (2014) also found similar results, as members of the BC and AB publics indicated they would be more willing to support forest biotechnology applications on public land if they resulted in additional benefits to society, the environment, or industry.

Males are $2.8 \%$ more likely to vote for any new forest policy over the current policy, while an additional year of age is associated with a $-0.2 \%$ change in likelihood of voting for a new policy. British Columbians are $8 \%$ less likely to vote for a new policy than Manitobans, 
410 while Albertans are 5\% more likely. Last, respondents living in centres with populations under

41110,000 and from 10,000-100,000 are 4\% less likely and 3\% more likely, respectively, to vote for

412 a new policy relative to those living in centres with populations greater than 100,000 . In the very

413 certain model, all coefficients for respondent-specific variables are of a greater magnitude than

414 in the all responses model. Males are $11 \%$ more likely to vote for a new policy over the status-

415 quo relative to females. An additional year of age is associated with a $0.3 \%$ decrease in the

416 likelihood of voting for a new policy. British Columbians are $14 \%$ less likely to vote for a new

417 policy over the current policy relative to Manitobans, and respondents living in population

418 centres under 10,000 are $8 \%$ less likely to vote for a new policy in comparison to those living in

419 large urban centres.

420 Respondent-specific characteristics generally exhibit low-magnitude or insignificant

421 relationships with acceptance of forest policies that include biotechnology applications. This is

422 not surprising, based on the lack of significant results found by Hajjar et al. (2014) and generally

423 inconsistent findings in GM food studies (e.g. Costa-Font et al. 2008). It seems that underlying

424 attitudes and values are better predictors of preferences than demographic characteristics (Costa-

425 Font et al.), which likely explains differences in demographic effects between different samples

426 and contexts. The finding that males are more likely to support forest biotechnology than females

427 is supported in some research (Hajjar et al, 2014; Costa-Font et al. 2008), although this

428 relationship is of low magnitude in the all responses model and moderate in the very certain

429 model. This relationship is perhaps partly explained by lesser perceptions of risk among males

430 (McFarlane 2005; Costa-Font et al. 2008). While older individuals often have lower perceptions

431 of risks (McFarlane 2005), the negative coefficient on age could be driven by lesser support for

432 biofuels, as Susaeta et al. (2010) found older respondents were less likely to purchase biofuels. 
433 However, this effect is of a low magnitude. Assuming a constant marginal effect of age on the

434 likelihood of voting for a new policy, there is only a $6 \%$ difference between a 20 year old and 50

435 year old in the all responses model, and a 9\% difference in the very certain model. The finding

436 that respondents living in small centres (under 10,000) or rural areas are less likely to vote for

437 change contradicts the findings of Hajjar et al. (2014); however, this result may be explained by

438 differences in how the data was segmented by population. Education is insignificant in

439 influencing forest policy acceptance, which is supported by Hajjar et al. (2014), but not

440 MacFarlane (2005) and numerous GM food studies (Costa-Font et al. 2008). However, these

441 differences in education level influences are likely explained by differences in context.

442 McFarlane's study examined perceptions of risk to forest biodiversity with minimal focus on

443 biotechnology, while GM food studies involve respondent considerations private health effects.

444 A number of reasons could lie behind the provincial differences in voting behaviour.

445 Forest composition and the economic contribution of the forest industry is quite different across

446 the provinces. For instance, the BC forest industry harvests more than 3 times the timber volume

447 than $\mathrm{AB}$ in a typical year, and more than 10 times the volume harvested by SK or MB (Natural

448 Resources Canada 2009). These differences are reflected, to some degree, in the differing

449 questionnaires provided in each province, and are therefore part of the estimated policy impacts

450 that rely on current situations in each province. To investigate these provincial differences, Table

4514 lists mean ratings of the importance of forest policy attributes on a 5-point scale $(1=$ not at all

452 important, $5=$ very important) by province. Differences in importance ratings between provinces

453 were tested using Kruskal-Wallis tests (Kruskal \& Wallis 1952). Significant differences were

454 found between provinces in importance ratings for breeding method, seed source, and the

455 policy's impact on land-use change (increase in non-harvested area). More specifically, BC 
456 residents, who were least likely to vote in favor of change, placed a significantly higher emphasis

457 on seed source and breeding method, while Albertans, who were most likely to vote in favour of

458 change, placed a significantly higher emphasis on changes to land-use.

\section{Conclusions}

This study examined public opinion of using poplars developed via genomics-assisted

462 breeding to be used as biofuel feedstock in British Columbia, Alberta, Saskatchewan and

463 Manitoba. Six new policy scenarios for each province were presented to respondents that

464 considered the use of three different breeding methods (traditional selective breeding, genomics-

465 assisted breeding, and GM), each with and without poplars being used for biofuels. We employ a

466 choice experiment to provide alternative outcomes to policy scenarios and to investigate

467 differences among characteristics of respondents. All proposed policy scenarios allowed

468 worldwide seed selection for poplars in each province on public land. Respondents were asked to

469 vote in a series of hypothetical referendums between each potential new policy and the current

470 policy, based on changes to forest land-use, breeding method, impact on industry, and impact on

471 carbon emissions.

472 Overall, there is substantial support (i.e. larger than a majority of respondents) for

473 allowing genetically improved poplars on public land if fibre is used to generate biofuels. This

474 support drops to approximately $25-45 \%$ of respondents if biofuels are not part of the scenario.

475 These drops in support are even more substantial if we only consider that part of the sample that

476 is very certain about their answers. In contrast, the various types of breeding technology do not

477 matter as much regarding public acceptance. Estimates from the probit models support these

478 general results. When all responses are considered, adding biofuels to a policy scenario increases

479 the likelihood of acceptance by $19-27 \%$, with amounts increasing as the level of breeding 
480 technology decreases. If only the very certain results are considered, all of the proposed policies

481 with biofuels are preferred relative to those with no biofuels, though there is no significant

482 variation in the acceptance of different breeding technologies if biofuel production is not a

483 component of the policy. Similar to the entire sample results, adding poplar-based biofuel

484 production to a policy scenario increases the likelihood of acceptance by $16.5-32 \%$, again, with

485 amounts increasing as the level of breeding technology decreases. Thus, the use of poplar as a

486 biofuel source increases the likelihood of the Canadian public choosing scenarios that allow the

487 application of new breeding technologies, such as genomics or GM, on public land.

488 Responses are different for segments of the population, but these differences do not

489 greatly influence choices. Attributes that increase the probability of acceptance are: being a male,

490 being from Alberta, and being from a population centre of 10,000-100,000 people (relative to

491 centers $>100,000)$. Attributes that decrease the probability of acceptance are age, being from

492 British Columbia, and being from a population centre of $<10,000$ (relative to centers $>100,000$ ).

493 Differences between provinces may arise due to two key reasons. First, the composition and

494 importance of the forest industry varies greatly across the western provinces. These differences

495 also resulted in different hypothetical referendum scenarios being presented in each province.

496 Second, the residents of each province placed different levels of importance on different policy

497 attributes. Specifically, BC residents, who were most opposed to forest biotechnology

498 applications on public land, placed the highest emphasis on seed source and breeding method. In

499 contrast $\mathrm{AB}$ residents, who were most in favor of using biotechnology on public lands, thought

500 that changes in land use were important aspects of policies.

501 Although results are somewhat similar between the all responses and very certain models, 502 substantial ambiguity remains in understanding public approval of genomic-assisted breeding in 
503 Canada. This ambiguity may arise due to the complexity involved with the variety of impacts

504 associated with changing policies. Despite our approach, which indicate specific attributes of

505 policy changes, there may be an underlying lack of understanding of what a forest policy

506 allowing genomic-assisted breeding on public land might look like, due to the variety of other

507 policy attributes and forestry practices that must change to allow genomic breeding programs.

508 Nonetheless, our results indicate that the public is highly responsive to policy outcomes, whether

509 good or bad, so gaining a better understanding of how applications of genomics in forestry may

510 impact society should allow for more clarity in understanding public preferences.

\section{Acknowledgements}

512

513 Funding for this research was provided by Genome Canada, Genome British Columbia, Genome

514 Alberta, and Alberta Innovates Bio Solutions.

\section{References}

516 Alberta Environment and Sustainable Resource Development. 2009. Alberta Forest Genetic

517 Resource Management and Conservation Standards. Report No. 978-0-7785-8467-4.

518 Alberta Environment and Sustainable Resource Development. 2013. Forest management

519 agreements: FMA holders [online]. Available from http://esrd.alberta.ca/lands-

520 forests/forest-management/forest-management-agreements/fma-holders.aspx [Accessed

$521 \quad$ November 2, 2013].

522 Anderson, J. A., Armstrong, G. W., Luckert, M. K., \& Adamowicz, W. L. 2012. Optimal zoning

523 of forested land considering the contribution of exotic plantations. Mathematical and

$524 \quad$ Computational Forestry \& Natural-Resource Sciences 4: 92-104.

525 Blumenschein, K., Johannesson, M., Blomquist, G. C., Liljas, B., O’Connor, R. M. 1998.

526 Experimental results on expressed certainty and hypothetical bias in contingent valuation. 

Southern Economic Journal, 65: 169-77. doi:10.2307/1061360.

528 Bogdanski, B. E. 2014. The rise and fall of the Canadian pulp and paper sector. The Forestry 529 Chronicle 90: 785-793. doi:10.5558/tfc2014-151.

530 British Columbia Ministry of Forest, Lands, and Natural Resource Operations. 2014. Timber

531 supply review: TSR and TSA schedule [online]. Available from

532 http://www.for.gov.bc.ca/hts/aactsa.htm [Accessed January 10, 2014].

533 Carson, R. T., \& Groves, T. 2007. Incentive and informational properties of preference 534 questions. Environmental \& Resource Economics 37: 181-210. doi:10.1007/s10640-007$535 \quad 9124-5$.

536 Costa-Font, M., Gil, J. M., \& Traill, W. B. 2008. Consumer acceptance, valuation of and 537 attitudes towards genetically modified food: Review and implications for food policy.

$538 \quad$ Food Policy 33: 99-111. doi:10.1016/j.foodpol.2007.07.002.

539 Fishbein, M. (1963). An investigation of the relationship between beliefs about an object and the $540 \quad$ attitude toward that object. Human relations 16: 233-239. doi:

$541 \quad \underline{10.1177 / 001872676301600302 .}$.

542 Genome British Columbia. 2014. Research Projects: POPCAN [online]. Available from

543 http://www.genomebc.ca/research-programs/projects/energy-mining-environment/popcan $544 \quad$ [Accessed October 28, 2014].

545 Genome Canada. 2014. Research Portfolio: Forestry [online]. Available from 546 http://www.genomecanada.ca/en/portfolio/project/forestry.aspx [Accessed December 12, $5472014]$.

548 Guigou Cairus, G. 2008. Estimating Genetic Flow Between Exotic and Native Poplar Species in 549 Quebec. MSc. Thesis, Faculty of Forestry and Geomatics, University of Laval, Quebec 
City, QC.

551 Hajjar, R., McGuigan, E., Moshofsky, M., \& Kozak, R. 2014. Opinions on strategies for forest

552 adaptation to future climate conditions in Western Canada: Surveys of the general public

553 and leaders of forest-dependent communities. Canadian Journal of Forest Research 44:

$554 \quad$ 1525-1533. doi:10.1139/cjfr-2014-0142.

555 Harshaw, H.W. 2012. Optimized Populus feedstocks and novel enzyme systems for a British

556 Columbia bioenergy sector: Understanding the social context of strategies to develop

557 biofuels from optimized Populus feedstocks - The British Columbia Bioenergy Survey.

558 Vancouver, BC: Department of Forest Resources Management, Faculty of Forestry, the

$559 \quad$ University of British Columbia.

560 Huber, P. J. 1967. The behavior of maximum likelihood estimates under nonstandard conditions.

561 In Proceedings of the fifth Berkeley symposium on mathematical statistics and

562 probability, Berkeley, Cal., 21 June - 18 July, 1965 and 27 December, 1965 - 7 January,

563 1966. Edited by Lucien M. Le Cam and Jerzy Neyman. Statistical Laboratory of the

564 University of California, Berkeley, Cal. pp. 221-233.

565 Kruskal, W. H., \& Wallis, W. A. 1952. Use of ranks in one-criterion variance analysis. Journal

566 of the American statistical Association 47: 583-621. doi:

$567 \quad 10.1080 / 01621459.1952 .10483441$.

568 LP Canada Ltd. 2014. Swan Valley forest management plan: documents [online]. Available from

569 http://www.swanvalleyforest.ca/documents.html [Accessed January 15, 2014].

570 Lusk, J. L., Jamal, M., Kurlander, L., Roucan, M., \& Taulman, L. 2005. A meta-analysis of

571 genetically modified food valuation studies. Journal of Agricultural and Resource

$572 \quad$ Economics 30: 28-44. 
573 Marciano, J. A., Lilieholm, R. J., Teisl, M. F., Leahy, J. E., \& Neupane, B. 2014. Factors

574 affecting public support for forest-based biorefineries: A comparison of mill towns and 575 the general public in Maine, USA. Energy Policy 75: 301-311.

576 doi:10.1016/j.enpol.2014.08.016.

577 McFarlane, B. L. 2005. Public perceptions of risk to forest biodiversity. Risk Analysis 25: 543$578 \quad$ 553. doi:10.1111/j.1539-6924.2005.00623.x.

579 Michaud, C., Llerena, D., \& Joly, I. 2012. Willingness to pay for environmental attributes of 580 non-food agricultural products: a real choice experiment. European Review of $581 \quad$ Agricultural Economics 40: 313-329. doi: 10.1093/erae/jbs025.

582 Minister of Justice. 2013. Renewable fuels regulations. Consolidated Regulation No. SOR/2010-

583 189. Available from http://laws-lois.justice.gc.ca/eng/regulations/SOR-2010-189/

$584 \quad$ [Accessed October 28, 2014].

585 Mistik Management Inc. 2013. Mistik forest management agreement area [online]. Available 586 from http://www.mistik.ca/fma.htm [Accessed November 3, 2014].

587 Natural Resources Canada. 2009. The state of Canada’s forests: annual report 2009. Cat. No. $588 \quad$ Fo1-6/2009e.

589 Pimentel, D., Marklein, A., Toth, M. A., Karpoff, M. N., Paul, G. S., McCormack, R., Kyriazis,

590 J., \& Krueger, T. 2009. Food versus biofuels: Environmental and economic costs. Human $591 \quad$ ecology 37: 1-12. doi:10.1007/s10745-009-9215-8.

592 Pin, R. R., \& Gutteling, J. M. 2009. The development of public perception research in the 593 genomics field: An empirical analysis of the literature in the field. Science

$594 \quad$ Communication 31: 57-83. doi:10.1177/1075547008327273. 
595 Ready, R. C., Champ, P. A., \& Lawton, J. L. 2010. Using respondent uncertainty to mitigate 596 hypothetical bias in a stated choice experiment. Land Economics 86: 363-381.

597 Rollins, C. 2015. Exploring Preferences for Poplar Biotechnology and Integrated Choice Latent

598 Variable Models. MSc. Thesis, Department of Resource Economics and Environmental 599 Sociology, University of Alberta, Edmonton, AB.

600 Saskaw Askiy Management Inc. 2013. Management area: Prince Albert FMA [online]. Available 601 from http://sakaw.ca/management_area.html [Accessed November 3, 2014].

602 Schmer, M. R., Vogel, K. P., Mitchell, R. P., \& Perrin, R. K. 2008. Net energy of cellulosic 603 ethanol from switchgrass. Proceedings of the National Academy of Sciences 105: 464604 469. doi:10.1073/pnas.0704767105

605 Shoostarian, A. (2015). Economics of Hybrid Poplar Plantations in Western Canada for 606 Bioethanol Production. MSc. Thesis, Department of Resource Economics and 607 Environmental Sociology, University of Alberta, Edmonton, AB.

608 Statistics Canada. 2012a. Population and dwelling counts, for Canada, provinces and territories, 609 census metropolitan areas and census agglomerations, 2011 and 2006 censuses (table). 610 Population and Dwelling Count Highlight Tables. 2011 Census. Statistics Canada 611 Catalogue no. 98-310-XWE2011002.

612 Statistics Canada. 2012b. 2011 National Household Survey. Statistics Canada Catalogue no. 99$613 \quad 012-X 2011040$.

614 Statistics Canada. 2013. Statistics Canada. Canadian Internet use survey, household access to the 615 Internet at home, by household income quartile, Canada and provinces. CANSIM 616 Table 358-0167. 
617 Susaeta, A., Alavalapati, J., Lal, P., Matta, J. R., \& Mercer, E. 2010. Assessing public

618 preferences for forest biomass based energy in the southern United States. Environmental

619 Management 45: 697-710. doi:10.1007/s00267-010-9445-y.

620 Tolko Industries Ltd. 2014. Annual harvest and renewal plan: operating plan [online]. Available 621 from http://www.tolkomanitoba.com/AOP.htm [Accessed January 17, 2015].

622 White, H. 1980. A heteroskedasticity-consistent covariance matrix estimator and a direct test for

623 heteroskedasticity. Econometrica 48: 817-838. doi:10.2307/1912934. 
624 Table 1. Outline of hypothetical referendum policy attributes for different forest biotechnology 625 policy and management approaches for each province.

626

\begin{tabular}{|c|c|c|c|c|c|}
\hline \multirow[b]{3}{*}{ Prov. } & \multirow[b]{3}{*}{ Policy } & \multicolumn{4}{|c|}{ Policy Attribute Levels } \\
\hline & & \multicolumn{2}{|c|}{$\begin{array}{c}\text { Commercial Forest } \\
\text { Land-Use }(\%) \\
\end{array}$} & \multirow{2}{*}{$\begin{array}{l}\text { Impact on } \\
\text { Industry }\end{array}$} & \multirow{2}{*}{$\begin{array}{c}\text { Carbon Emission } \\
\text { Reduction } \\
\text { (Cars per year) }\end{array}$} \\
\hline & & $\begin{array}{c}\text { Non- } \\
\text { Harvested }\end{array}$ & $\begin{array}{l}\text { Improved } \\
\text { Poplar }\end{array}$ & & \\
\hline \multirow[t]{7}{*}{$\mathrm{AB}$} & Current & $40 \%$ & $<0.1 \%$ & & \\
\hline & Trad no BF & $46 \%$ & $3 \%$ & Small & \\
\hline & Trad + BF & $46 \%$ & $3 \%$ & Small & 120,000 \\
\hline & Genome no BF & $48 \%$ & $3 \%$ & Moderate & \\
\hline & Genome + BF & $48 \%$ & $3 \%$ & Moderate & 120,000 \\
\hline & GM no BF & $49 \%$ & $3 \%$ & Strong & \\
\hline & $\mathrm{GM}+\mathrm{BF}$ & $49 \%$ & $3 \%$ & Strong & 120,000 \\
\hline \multirow[t]{7}{*}{$\mathrm{BC}$} & Current & $40 \%$ & $<0.1 \%$ & & \\
\hline & Trad no BF & $42 \%$ & $1 \%$ & Little to no & \\
\hline & $\operatorname{Trad}+\mathrm{BF}$ & $42 \%$ & $1 \%$ & Little to no & 90,000 \\
\hline & Genome no BF & $43 \%$ & $1 \%$ & Small & \\
\hline & Genome + BF & $43 \%$ & $1 \%$ & Small & 90,000 \\
\hline & GM no BF & $43 \%$ & $1 \%$ & Moderate & \\
\hline & $\mathrm{GM}+\mathrm{BF}$ & $43 \%$ & $1 \%$ & Moderate & 90,000 \\
\hline \multirow[t]{7}{*}{ MB } & Current & $60 \%$ & $<0.1 \%$ & & \\
\hline & Trad no BF & $63 \%$ & $2 \%$ & Small & \\
\hline & Trad + BF & $63 \%$ & $2 \%$ & Small & 30,000 \\
\hline & Genome no BF & $64 \%$ & $2 \%$ & Moderate & \\
\hline & Genome + BF & $64 \%$ & $2 \%$ & Moderate & 30,000 \\
\hline & GM no BF & $65 \%$ & $2 \%$ & Strong & \\
\hline & $\mathrm{GM}+\mathrm{BF}$ & $65 \%$ & $2 \%$ & Strong & 30,000 \\
\hline \multirow[t]{7}{*}{ SK } & Current & $40 \%$ & $<0.1 \%$ & & \\
\hline & Trad no BF & $46 \%$ & $3 \%$ & Small & \\
\hline & Trad + BF & $46 \%$ & $3 \%$ & Small & 50,000 \\
\hline & Genome no BF & $48 \%$ & $3 \%$ & Moderate & \\
\hline & Genome + BF & $48 \%$ & $3 \%$ & Moderate & 50,000 \\
\hline & GM no BF & $49 \%$ & $3 \%$ & Strong & \\
\hline & $\mathrm{GM}+\mathrm{BF}$ & $49 \%$ & $3 \%$ & Strong & 50,000 \\
\hline
\end{tabular}


628 Table 2 - Comparison of socio-demographic characteristics between the 2014 sample used for 629 this study (N) and 2011 Canada census data (pop.) for Alberta, British Columbia, Manitoba, and 630 Saskatchewan.

631

\begin{tabular}{lcccccccc}
\hline & \multicolumn{1}{c}{ Province } \\
\cline { 2 - 9 } & \multicolumn{2}{c}{ AB } & \multicolumn{1}{c}{ BC } & \multicolumn{2}{c}{ MB } & \multicolumn{3}{c}{ SK } \\
\cline { 2 - 9 } Characteristic & $\mathrm{N}$ & Pop. & $\mathrm{N}$ & Pop. & $\mathrm{N}$ & Pop. & $\mathrm{N}$ & Pop. \\
\hline Number of Respondents & 1205 & - & 1248 & - & 502 & - & 500 & - \\
Male (\%) & 42 & 51 & 44 & 49 & 42 & 49 & 40 & 50 \\
Average Age (18+) & 48 & 45 & 49 & 48 & 50 & 47 & 50 & 47 \\
Population of Centre of & & & & & & & & \\
Residence (\%) & & & & & & & & \\
$\quad>100,000$ & 57 & 68 & 51 & 68 & 58 & 60 & 49 & 46 \\
$\quad$ 10,000-100,000 & 22 & 13 & 31 & 19 & 13 & 8 & 16 & 20 \\
$\quad<10,000$ & 21 & 18 & 18 & 12 & 29 & 32 & 35 & 34 \\
Post-Secondary Education & 67 & 55 & 61 & 56 & 60 & 47 & 59 & 47 \\
Attained (\%) & & & & & & & & \\
\hline
\end{tabular}

Education data from Statistics Canada (2012b); all other data from Statistics Canada (2012a). 
633 Table 3 - Coefficient, standard error (SE) and marginal effect (ME) estimates from binary probit 634 models explaining the importance of factors affecting hypothetical forest policy referendum 635 votes.

636

\begin{tabular}{|c|c|c|c|c|c|c|}
\hline \multirow[b]{2}{*}{ Variable } & \multicolumn{3}{|c|}{ All Responses } & \multicolumn{3}{|c|}{ Very Certain Responses } \\
\hline & Coef. & $\mathrm{SE}$ & $\mathrm{ME}$ & Coef. & $\mathrm{SE}$ & $\mathrm{ME}$ \\
\hline Male & $0.071^{*}$ & 0.032 & $0.028 *$ & $0.288^{*}$ & 0.070 & $0.107^{*}$ \\
\hline Age & $-0.005^{*}$ & 0.001 & $-0.002 *$ & $-0.009 *$ & 0.002 & $-0.003^{*}$ \\
\hline Post-Sec. Education & -0.036 & 0.033 & -0.014 & -0.037 & 0.074 & -0.014 \\
\hline $\mathrm{AB}$ & $0.126^{*}$ & 0.052 & $0.051 *$ & 0.108 & 0.113 & 0.040 \\
\hline $\mathrm{BC}$ & -0.209 & 0.052 & $-0.083 *$ & $-0.383 *$ & 0.112 & $-0.138^{*}$ \\
\hline SK & 0.085 & 0.062 & 0.034 & 0.097 & 0.136 & 0.036 \\
\hline \multicolumn{7}{|l|}{ Population: } \\
\hline$<10,000$ & $-0.096 *$ & 0.040 & $-0.038 *$ & $-0.214^{*}$ & 0.089 & $-0.077^{*}$ \\
\hline $10,000-100,000$ & 0.084 & 0.041 & $0.034^{*}$ & 0.038 & 0.089 & -0.014 \\
\hline \multicolumn{7}{|l|}{ Policy Scenarios: } \\
\hline \multicolumn{7}{|l|}{ Trad no BF (excluded) } \\
\hline Trad $+B F$ & $0.708 *$ & 0.025 & $0.274 *$ & $0.832 *$ & 0.051 & $0.321 *$ \\
\hline Genome nо BF & $0.099 *$ & 0.021 & $0.040 *$ & -0.003 & 0.047 & -0.001 \\
\hline Genome + BF & $0.652 *$ & 0.025 & $0.253 *$ & $0.699 *$ & 0.052 & $0.270^{*}$ \\
\hline$G M$ no $B F$ & $0.110^{*}$ & 0.023 & $0.044 *$ & -0.040 & 0.050 & -0.015 \\
\hline$G M+B F$ & $0.488^{*}$ & 0.026 & $0.192 *$ & $0.430 *$ & 0.053 & $0.165^{*}$ \\
\hline Constant & $0.155^{*}$ & 0.078 & - & -0.172 & 0.170 & - \\
\hline McFadden's $\mathrm{R}^{2}$ & & 0.049 & $\bar{c}$ & & 0.098 & \\
\hline Votes & & 20730 & & & 4927 & \\
\hline (Respondents) & & $(3455)$ & & & $(1561)$ & \\
\hline $\begin{array}{l}\text { Log-Pseudo- } \\
\text { Likelihood }\end{array}$ & \multicolumn{3}{|c|}{-13626.725} & \multicolumn{3}{|c|}{-2906.0523} \\
\hline$\%$ Correct Predictions & \multicolumn{3}{|c|}{61} & \multicolumn{3}{|c|}{68} \\
\hline
\end{tabular}


638 Table 4 - Importance of policy attributes when voting by province.

639

\begin{tabular}{lcccc}
\hline & \multicolumn{4}{c}{ Mean Importance $^{\text {P }}$} \\
\cline { 2 - 5 } Policy Attribute & \multicolumn{4}{c}{ Province } \\
\cline { 2 - 5 } & $\mathrm{AB}$ & $\mathrm{BC}$ & $\mathrm{MB}$ & $\mathrm{SK}$ \\
\hline Breeding Method* & 3.85 & 4.01 & 3.91 & 3.84 \\
Seed Source (location)* & 3.92 & 4.01 & 3.91 & 3.95 \\
Land-Use Change* $_{\text {Carbon Emissions (biofuels) }}$ & 3.88 & 3.78 & 3.84 & 3.78 \\
Impact on Industry & 3.94 & 3.88 & 3.89 & 3.90 \\
\hline
\end{tabular}

'For each policy attribute, respondents were asked, "For each factor listed, please tell us how important it was in influencing your decisions of which policy to vote for (1 being not at all important and 5 being very important)".

* Indicates significant difference found between provinces above the $95 \%$ confidence level as determined by Kruskal-Wallis test. 


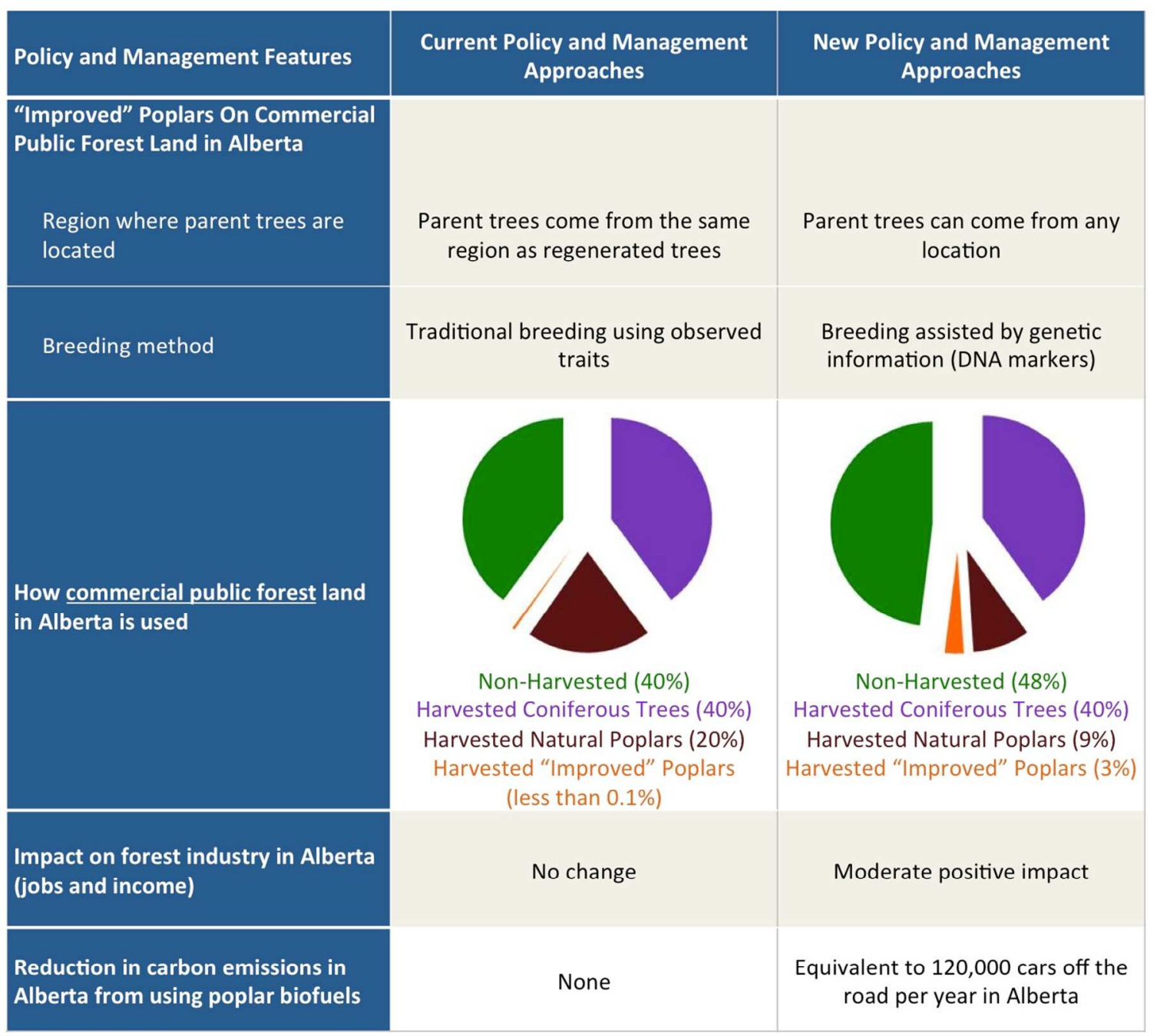

Above each table, respondents were asked, "Consider the two scenarios below. Would you vote for the current situation or the new policy option if you were voting in a provincial referendum?"

Figure 1 - Example of a hypothetical referendum question (Genome $+B F$ scenario) used to measure public preferences for using different Poplar breeding technologies for use on public 647 land. 


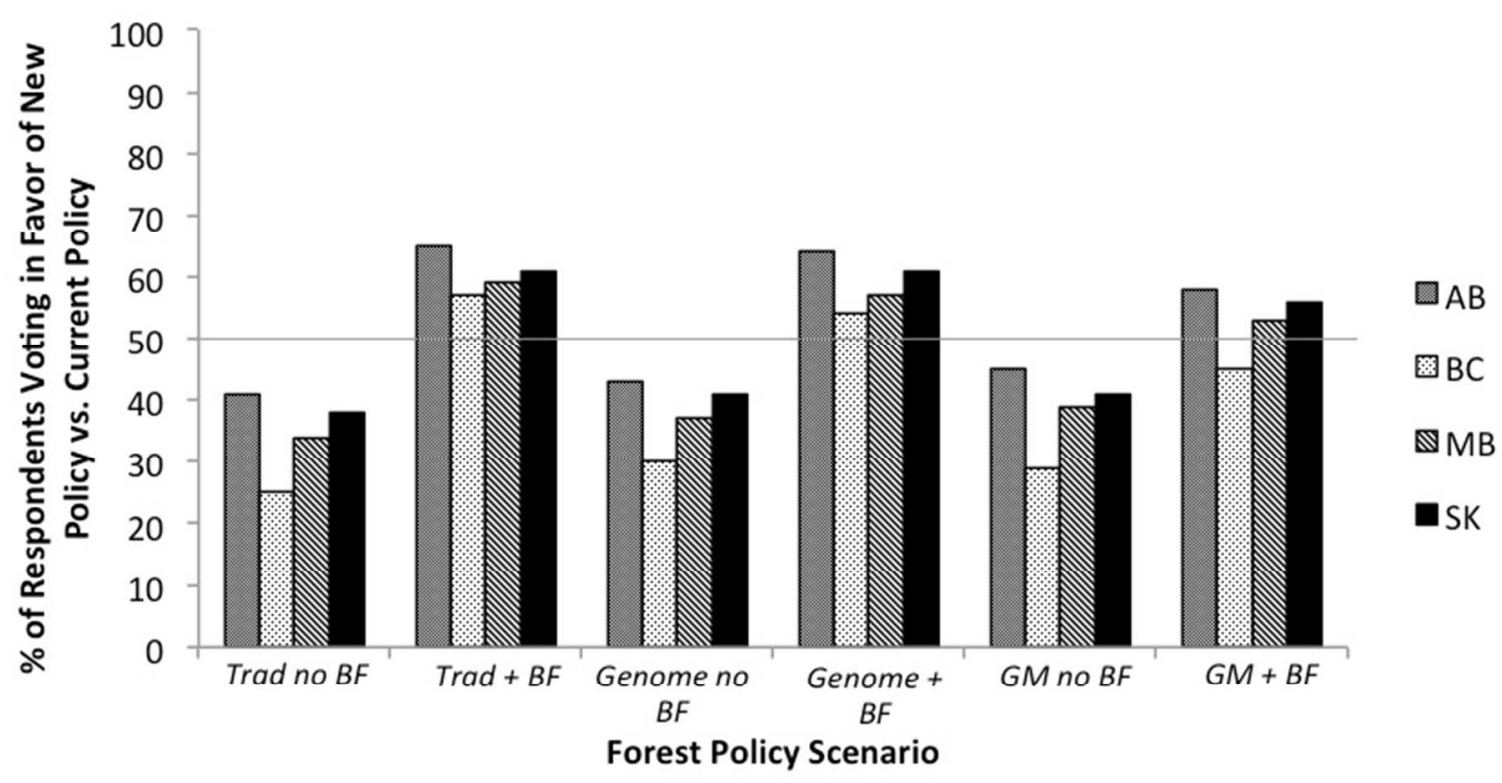

648

649

650

651

652

Figure 2 - Percentages of all respondents voting in favor of forest policies involving different breeding methods (traditional, genomic-assisted, and genetic modification) and biofuel (BF) production over the current provincial policy situation in Alberta, British Columbia, Manitoba, and Saskatchewan. 


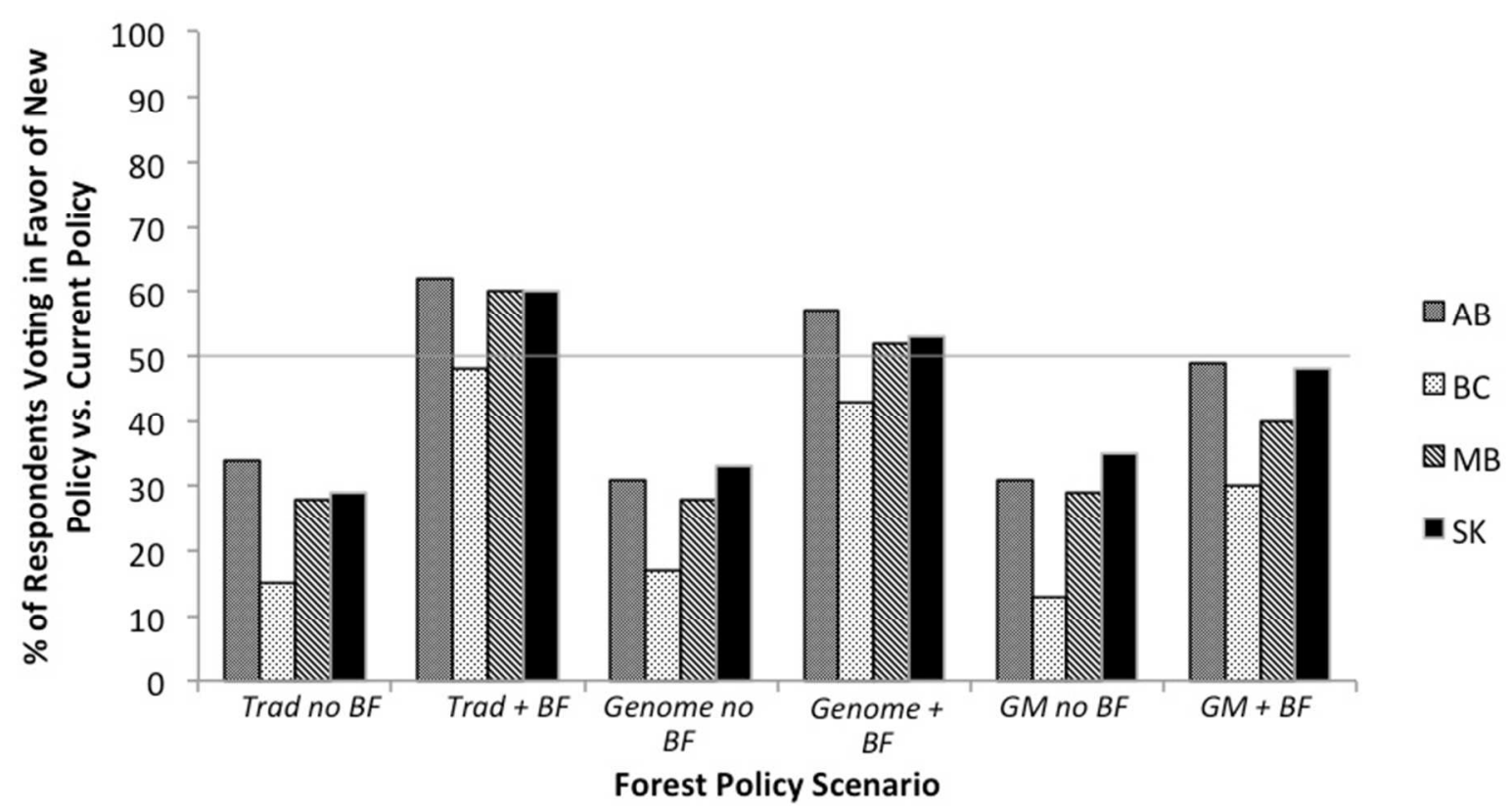

Figure 3 - Percentages of respondents who indicated they were very certain of their response voting in favor of forest policies involving different breeding methods (traditional, genomicassisted, and genetic modification) and biofuel (BF) production over the current provincial policy situation in Alberta, British Columbia, Manitoba, and Saskatchewan. 